\title{
СПОСОБЫ ЗАКЛЮЧЕНИЯ СОГЛАШЕНИЯ \\ ОБ ЭЛЕКТРОННОМ ВЗАИМОДЕЙСТВИИ \\ С ПОМОЩЬЮ ИНЫХ ТЕХНИЧЕСКИХ СРЕДСТВ
}

\begin{abstract}
Кузьмина Анастасия Игоревна
студент

Научный руководитель: Агибалова Елена Николаевна

к.ю.н., доцент

Волгоградский институт управления

филиал ФГБОУ ВО «Российская академия народного хозяйства и государственной службы при Президенте Российской Федерации»
\end{abstract}

\begin{abstract}
Аннотация: В статье идет речь о способах заключения соглашения об электронном взаимодействии с помощью иных технических средств, исследуются особенности этих способов, анализируется судебная практика по заключению электронных соглашений, делается вывод о необходимости совершенствования понятийного аппарата, законодательного закрепления способов заключения соглашения об электронном взаимодействии.

Ключевые слова: электронные сделки, электронное взаимодействие, электронное соглашение, иные технические средства, интернет, онлайн, цифровизация, сделки.
\end{abstract}

\section{METHODS OF CONCLUDING AN AGREEMENT ON ELECTRONIC INTERACTION USING OTHER TECHNICAL MEANS}

\section{Kuzmina Anastasia Igorevna Agibalova Elena Nikolaevna}

\begin{abstract}
The article deals with the methods of concluding an agreement on electronic interaction using other technical means, examines the features of these methods, analyzes judicial practice on the conclusion of electronic agreements, concludes that it is necessary to improve the conceptual apparatus, legislative consolidation of the methods of concluding an agreement on electronic interaction.
\end{abstract}


Key words: electronic transactions, electronic interaction, electronic agreement, other technical means, Internet, online, digitalization, transactions.

2019 год был ознаменован годом реформы гражданского оборота. Трансформация оказала сильное влияние на институт сделок, которая позволила «говорить» об использовании электронных сделок. При этом разгорелась поистине интересная дискуссия среди цивилистов о том, является ли электронная сделка самостоятельной формой сделки или это подвид простой письменной формы сделки. По нашему мнению, электронная сделка является разновидностью простой письменной формы сделки.

Стоит заметить, что заключение сделок в электронной форме допускалось и раньше, если документ выражал содержание сделки и подписывался уполномоченным лицом. В ст. 6 Ф3 № 63-Ф3 отмечены условия признания электронных документов, подписанных электронной подписью, равнозначными документам на бумажном носителе [1].

В действующей редакции абз. 2 п. 1 ст. 160 Гражданского кодекса РФ (далее - ГК РФ) гласит: «письменная форма сделки считается соблюденной также в случае совершения лицом сделки с помощью электронных либо иных технических средств, позволяющих воспроизвести на материальном носителе в неизменном виде содержание сделки, при этом требование о наличии подписи считается выполненным, если использован любой способ, позволяющий достоверно определить лицо, выразившее волю» [2].

Из содержания абзаца прямо следует следующее:

1) сделки теперь возможно совершать с помощью электронных либо иных технических средств;

2) средства, применяемые при совершении сделки, позволяют воспроизвести на материальном носителе в неизменном виде содержание сделки;

3) способ, выбранный для подписи, должен достоверно определять лицо, выразившее волю.

Законодатель не дает определение понятия электронной сделки в ГК РФ. По нашему мнению, электронная форма сделки - это заключение соглашения между сторонами в форме, пригодной для восприятия человеком через электронно-вычислительную машину или путем передачи через информационно-телекоммуникационную сеть «Интернет», заверенной 
электронной подписью или иным техническим средством в пределах, допускаемых законом и иными правовыми актами [3, с. 218].

Аналогичная ситуация складывается и с понятием «иные технические средства», поскольку законодатель акцентирует на них внимание, но не дает легального определения. Исследовав эту проблемы, мы пришли к выводу, что под иными техническими средствами предполагаются любые средства, связанные с электронными технологиями [4, с. 83]. Иные технические средства являются вспомогательными средствами при заключении электронных сделок.

Многообразие способов заключения электронных сделок объясняется стремительным развитием информационных технологий. Рассмотрим некоторые из них подробнее.

Первым классическим примером способа заключения электронного соглашения является электронный образ документа, т.е. документ, созданный посредством сканирования оригинального бумажного документа. В этом случае можно говорить о применении такого технического средства как PortableDocumentFormat (далее - PDF, что в переводе с английского языка на русский означает формат переносимого документа). Благодаря средству PDF в документ не могут быть внесены какие-либо изменения, что является гарантией для контрагента получить исходный документ, который был направлен акцептантом. Можно говорить и о безопасности второй стороны, а также о невозможности экстраполирования сделки к простой письменной форме, так как ее заключение будет требовать в ответ только электронную подпись.

Как справедливо отмечено в абз. 4 п. 1 постановления Пленума Верховного Суда РФ № 57, электронный образ документа - это сканированная копия документа, переведенная в электронную форму, заверенная электронной подписью [5]. Исходя из этого, можно определить следующее:

1) электронный образ документа использует PDF как иное техническое средство для «оцифровки» документа и конвертации из бумажного вида в электронный;

2) электронный образ документа должен быть подписан электронной подписью, которую в свою очередь также рассматривают как иное техническое средство.

Вторым способом заключения электронного взаимодействия выступают сообщения в мессенджерах. На данном этапе развития они набирают 
стремительную популярность, так как пользователи активно используют различные мессендж-приложения не только для общения, обмена информацией, но и для согласования существенных условий сделки, обмена документами по соглашению и т.п.

Законодатель не указывает на прямое использование мессенджеров, однако стоит обратить внимание на фразу п. 2 ст. 434 ГК РФ: «... в том числе электронными документами, передаваемыми по каналам связи». Представляется, что именно под каналами связи подразумеваются мессенджеры. Поскольку технология использования мессенджеров проста (регистрация через логин (например, телефон, e-mail) и пароль), то обмен сообщениями с передачей файлов можно и нужно отнести к обмену электронными документами. Сложности возникают на этапе судебных разбирательств при представлении доказательств, так как существует проблема идентификации сторон договора, оценка переписки на предмет переговоров или оферты, акцепта.

Во-первых, идентификация сторон относится к субъективному восприятию договаривающихся сторон (например, через фото, установленное на заставку абонента, персонифицированный номер телефон и т.д.).

Во-вторых, не всегда понятны из переписки намерения сторон, поэтому квалификация переговоров, оферты или акцепта представляется крайне сложным процессом.

Однако в данных вопросах судебная практика не столь однозначна. Так, между ООО и ИП сложилась деловая коммуникация посредством использования мессенджера - Telegram. От имени ООО переписку вел сотрудник, у которого не было на это полномочий или доверенности на совершение таких действий в интересах и от меня компании. По условиям договора исполнитель должен был наладить информационное сопровождение и продвижение проекта во всех социальных сетях, к которым у заказчика был доступ. Вся переписка, согласование условий, подписание договора шли через Telegram. Исполнитель оказывал требуемые от него услуги, заказчик внес первый взнос оплаты, но в последствии отказался оплачивать остальную часть оказанных услуг и подал в суд иск о неосновательном обогащении, а также настаивал на том, что никакого договора стороны не заключали, а переписка в Telegram не является доказательством, тем более что переписку вело лицо, у которого не было на это полномочий. Суд, изучив все представленные 
доказательства, удовлетворил полностью иск и признал договор возмездного оказания услуг заключенным с нарушением законодательства РФ [6].

Иную позицию занял Девятый Арбитражный Апелляционный суд по делу № 09АП-7765/2020. Так, между сторонами был заключен договор поставки через WhatsApp. Как справедливо отметил суд, отсутствие оригиналов договора не влечет их незаключённости или заключенности с нарушением законодательства РФ либо недействительности [7].

Целесообразно отметить, что на данный момент суды исходят из субъективного мнения при оценке доказательств интернет-переписок, но, как нам представляется, совсем скоро ввиду развития технического прогресса, законодатель произведет официальную регламентацию такого способа заключения электронного взаимодействия.

Следующим способом заключения электронной сделки необходимо назвать обмен документами по электронной почте. Специфичность способа заключается в том, что пользователи созданных электронных ящиков обмениваются электронными документами, согласовывают существенные условия договора, подписывают различные соглашения. Данный способ, в отличие от предыдущего, позволяет достоверно установить факт переговоров, оферты или акцепта. При этом важно отметить, что при ведении переписки необходимо использовать официальную почту юридического лица, индивидуального предпринимателя, так как именно при таком использовании будет легче определить стороны соглашения, их намерения и уполномоченность на совершение таких действий.

Позиция судов также неоднозначна по данному вопросу. Например, между ООО и АО был заключен договор аренды транспортного средства без экипажа. Обмен документами и достижение соглашения осуществлялось через электронную почту. Ответчик отрицал правомерность такого способа заключения, но суд, заслушав все доводы сторон, пояснил, что позиция ответчика в том, что договор не был заключен, является необоснованной [8] и обратил внимание на пп. 2, 3 ст. 434 ГК РФ о том, что обмен может совершаться электронными документами, передаваемыми по каналам связи.

В другом случае суд пришел к выводу, что электронный адрес, используемый для переписки при отсылке накладных по договору, не позволяет однозначно установить факт направления соответствующих документов непосредственно стороне договора [9]. 
Проанализировав судебную практику по комментируемому способу заключения электронного соглашения, можно сделать следующие выводы:

1) обмен документами по электронной почте подтверждает наличие реальных отношений с систематическим документооборотом в электронной форме, но исключает возможность использования других форматов коммуникаций;

2) переговоры по согласованию существенных условий легко подтвердить перепиской по электронной почте;

3) имеет место упрощенный способ установления контрагентов в доменах электронных адресов, но при этом не всегда суд учитывает правомерность использования того или иного имени в электронной почте;

4) пересылка документов, как правило, ведется с указанием всех реквизитов не только в пересылаемых документах, но и в подписи электронного письма, однако зачастую отсутствует ясность относительно полномочий лица на совершение тех или иных действий.

Четвертым способом заключения электронного соглашения является смарт-контракт с применением технологии блокчейн. При этом важно отметить сразу, что смарт-контракт, по нашему мнению, не является иным техническим средством, поскольку это сделка, направленная на возникновение, изменение или прекращение правоотношений между сторонами, а вот технология блокчейн - классический пример иного технического средства.

Применительно к блокчейну ученые отмечают, что это специфическая информационная система, представляющая собой реестр информации, а также технологию ее обработки, включающую накопление (создание), хранение точных данных, подтверждающих совокупность имущественных и иных прав и обязанностей их владельцев [10, с. 165]. Известно, что смарт-контракт прописан в виде программного кода в блокчейне и изначально был придуман для программистов. Е.Н. Агибалова в своем исследовании проводит анализ смарт-контракта с применением технологии блокчейн и приходит к выводу, что определение смарт-контрактов должно быть технологически нейтральным, a, соответственно, блокчейн не может стать частью определения смарт-контрактов. Как справедливо отмечает автор, существование смарт-контрактов не должно ограничиваться применением технологии блокчейн [11, с. 176, 178]. 
В частности, при заключении договора купли-продажи используется информационная система, происходит оцифровка договора, денег, клиринг и право собственности подтверждается автоматически, и стороны приходят к логическому завершению правоотношений, благодаря блокчейну как иному техническому средству при заключении смарт-контракта.

В качестве способа заключения соглашения об электронном взаимодействии целесообразно выделить онлайн-договор. Для рассмотрения такого способа следует разобраться в видах электронной подписи, которые придают юридическую силу таким договорам.

Статья 5 Ф3 № 63-Ф3 выделяет следующие виды подписей:

1. Простая электронная подпись (использование кодов, паролей или иных средств, подтверждающих факт формирования подписи).

2. Усиленная электронная подпись (усиленная неквалифицированная электронная подпись - подпись, полученная в результате криптографического преобразования, с использованием ключа подписи; усиленная квалифицированная электронная подпись - подпись, содержащая в себе все признаки неквалифицированной подписи и имеющая ключ проверки в сертификате, выдаваемый специальным уполномоченным органом, а также наличие подтвержденных требований для создания и проверки электронной подписи).

Онлайн-договор можно разделить на:

1) очевидную оферту на заключение соглашения, расположенную на сайте в пространстве «Интернет» (классический пример - оформление потребительского кредита в личном кабинете «Сбербанк-онлайн»);

2) наличие общих условий - онлайн на сайте контрагента, а индивидуальных условий - офлайн (например, при оформлении кредитной карты в личном кабинете «Сбербанк-онлайн» прописаны общие условия, а индивидуальные условия рассказывают при личном посещении банка во время выдачи пластиковой карты на руки);

3) наличие только индивидуальных условий - онлайн (например, персональный тариф мобильной сети используемого оператора только определенному абоненту).

Одним из интереснейших способов заключения электронных соглашений важно выделить агрегаторы совместно с такими средствами как click-wrap и browse-wrap. 
В дискуссии на одной из творческих мастерских III-го Международного конгресса по цивилистической компаративистике «Мозолинские чтения 2021» (г. Москва, 9-11 декабря 2021 г., Московский государственный юридический университет имени О.Е. Кутафина (МГЮА)) была озвучена точка зрения, согласно которой агрегаторы - это новые участники гражданского оборота. Правомерно ли так думать? Вопрос крайне сложный и весьма дискуссионный. На наш взгляд, агрегатор - это вид иного технического средства, который получил в современном мире большое распространение в электронной коммерции [12, с. 127], подразумевающий под собой посредника (помощника) при заключении договора купли-продажи через «Интернет».

В п. 2 ст. 497 ГК РФ предусмотрен дистанционный способ продажи [13]. В качестве примера можно привести интернет-магазин Wildberries, который специализируется на доставке товара путем оформления электронного договора купли-продажи через приложение на телефоне и (или) в личном кабинете через компьютер. При этом оплата может быть произведена как в самом приложении до фактической доставки, так и в день поставки товара на дом или в пункте самовывоза. Безусловно, у данного технического средства есть как плюсы, так и минусы. Одним из главных плюсов для покупателей является сэкономленное время. Минусы - требование предоплаты, мошенничество, риск распространения информации, переданной продавцу. Что касается продавца, то он несет определенный риск в виду отказа от товара, его возврата, задержки сроков поставки, информационных сбоев, угрозы атак хакеров и т.п.

Click-wrap, что в переводе с английского языка на русский означает клик мышью, предполагает отображение информации на сайте, которая содержит условия сделки и будет являться офертой на предложенный акцепт с момента нажатия на условие «я согласен(-а)» [14, с. 208]. Однако гражданскоправовая природа таких сделок очень противоречива, так как, с одной стороны, при их совершении соблюдены все правила сделки, которые позволяют сказать о конклюдентных действиях, а, с другой, законодатель признает это электронным документооборотом. Особенностью клика мышью стоит признать очевидное волеизъявление на совершение сделки. Примером для такой сделки будет являться тот же магазин Wildberries. Таким образом, можно говорить, что агрегатор в сочетании с кликом мышью способствует заключению электронной сделки. 
Browse-wrap представляет собой способ заключения договора с предоставлением доступа к материалам на веб-сайтах или загружаемому продукту и их использованию. Особенность такого способа проявляется в том, что волеизъявление на совершение сделки в очевидной форме отсутствует и фактически речь идет о заключении договора посредством конклюдентных действий. $\mathrm{B}$ качестве примера можно привести пользовательское соглашение, которое мы «подписываем» по умолчанию, посещая интернет-сайты.

Резюмируя, отметим, что в настоящее время постепенно появляются новые способы заключения соглашения об электронном взаимодействии с помощью иных технических средств, большинство из которых, к сожалению, не регламентируются на законодательном уровне. Суды исходят из субъективного мнения при оценке доказательств, что ведет к появлению неоднозначной судебной практики. Для устранения таких пробелов предлагаем следующее:

1. Усовершенствовать понятийный аппарат в отношении терминов: «электронная сделка», «иные технические средства», «онлайн-договоры», «смарт-контракт», «блокчейн», «агрегатор», «click-wrap», «browse-wrap».

2. Законодательно закрепить положения, регламентирующие способы заключения соглашения об электронном взаимодействии с помощью иных технических средств.

3. Разъяснить судам порядок признания электронных переписок достоверным доказательством заключения электронных соглашений.

\section{Список литературы}

1. Федеральный закон от 06 апреля 2011 г. № 63-Ф3 (ред. от 11.06.2021) «Об электронной подписи»// Собрание законодательства РФ. 2011. - № 15. - Ст. 2036.

2. Гражданский кодекс Российской Федерации (часть первая) от 30 ноября 1994 г. №51-Ф3 (ред. от 28.06.2021, с изм. от 26.10.2021) // Собрание законодательства РФ. - 1994. - № 32. - Ст. 3301.

3. Агибалова Е.Н., Кузьмина А.И. К вопросу о безопасности совершения нотариальных сделок в электронной форме либо с помощью иных технических средств // Безопасность в современном мире. Часть 2: материалы III Всероссийской научно-практической конференции с международным 
участием / отв. ред. С.А. Бондарева; Волгоградский институт управления филиал ФГБОУ ВО «Российская академия народного хозяйства и государственной службы». - Волгоград: Изд-во Волгоградского института управления - филиала РАНХиГC, 2021. - 1 электрон. опт. диск (CD-ROM). Систем. требования: IBM PC с процессором 486; ОЗУ 64 Мб; CD-ROM дисковод; Adobe Reader 6.0. Загл. с экрана. - С. 217-222.

4. Агибалова Е.Н., Кузьмина А.И. Сделки, совершаемые с помощью электронных либо иных технических средств // Всероссийский юридический форум: сборник статей Всероссийского юридического форума (26 октября 2020 г.). - Петрозаводск: МЦНП «Новая наука», 2020. - С. 81-87.

5. Постановление Пленума Верховного Суда РФ от 26 декабря 2017 г. № 57 «О некоторых вопросах применения законодательства, регулирующего использование документов в электронном виде в деятельности судов общей юрисдикции и арбитражных судов». - URL: http://www.consultant.ru/ document/cons_doc_LAW_286321/ (дата обращения: 12.12.2021).

6. Решение Арбитражного суда города Москвы от 15 ноября 2019 г. по делу № A40-93872/19-34-763. - $\quad$ URL: https://kad.arbitr.ru/Document/ Pdf/40534276-39cc-40b1-833c-4201f23b05bd/3df0ad68-56bb-4c7a-b2ef-8274f70 8464c/A40-93872-2019_20191115_Reshenija_i_postanovlenija.pdf? isAddS tamp= True (дата обращения: 12.12.2021).

7. Постановление Девятого Арбитражного Апелляционного суда № 09АП-7765/2020 от 25 марта 2020 г. по делу № A40-278013/2019. - URL: https://kad.arbitr.ru/Document/Pdf/cb6ce3c9-c068-4e90-8041-7638f7be0dde/bc290 7ba-e50f-488a-b2af-ad03e71e144a/A40-278013-2019_20200325_Postanovlenie_ apelljaci onnoj_instancii.pdf?isAddStamp=True (дата обращения: 12.12.2021).

8. Решение Арбитражного суда города Москвы от 23 ноября 2018 г. по делу № A40-164376/16150-1449. - URL: https://kad.arbitr.ru/Document/ Pdf/1f4bfdc4-e496-4be7-8981-f2a02557bce7/f8b3d9e6-1258-4954-8cd5-1a318ca 38ecb/A40-164376-2016_20181123_Reshenija_i_postanovleni ja.pdf? isAddStamp $=$ True (дата обращения: 12.12.2021).

9. Решение Арбитражного суда Республики Крым от 31 мая 2017 г. по делу № A83-8281/2016. - URL: https://kad.arbitr.ru/Document/Pdf/377a54b362f4-4f08-aba8-07e5f986b819/58f92dcc-5bdb-49f8-8e27-86755cdb0fad/A838281-2016_20170531_Reshenija_i_postanovlenija.pdf?isAddStamp=True (дата обращения: 12.12.2021). 
10. Agibalova E.N., Ilovaysky I.B., Kayl Y.Y., \& Usanova V.A. (2020). Use of Letter of Credit Form of Payment in the Implementation of Smart Contracts and Blockchain Technology. In Popkova E., Sergi B. (Ed.), Scientific and Technical Revolution: Yesterday, Today and Tomorrow. ISC 2019. Lecture Notes in Networks and Systems (Vols. 129). Switzerland, Cham: Springer, 2020. P. 160-170.

11. Agibalova E.N. (2020). Blockchain Technology in Smart Contracts: Is It a Constitutive Attribute or a Technological Neutrality? In Popkova E., Sergi B. (Ed.), Scientific and Technical Revolution: Yesterday, Today and Tomorrow. ISC 2019. Lecture Notes in Networks and Systems (Vols. 129). - Switzerland, Cham: Springer, 2020. - P. 171-180.

12. Потапенко С.В., Сметанникова С.С. Товарные агрегаторы как информационные посредники в электронной коммерции // Вестник Краснодарского университета МВД России. -2018. -№ 3 (41). - С. 127-131.

13. Гражданский кодекс Российской Федерации (часть вторая) от 26 января 1996 г. №14-Ф3 (ред. от 01.07.2021, с изм. от 08.07.2021) // Собрание законодательства РФ. - 1996. - № 5. - Ст. 410.

14. Козловская С.В. Проблемы гражданско-правового регулирования сделок, заключаемых в рамках электронного взаимодействия // Опыты цивилистического исследования: Сборник статей (выпуск 2) / рук. авт. кол. и отв. ред. А.М. Ширвиндт, Н.Б. Щербаков. - М: Статут, 2018. - С. 195-230. 